\title{
Wind/PV/storage independent system capacity configuration model and scheduling policy analysis
}

\author{
Lin-Jing $\mathrm{Hu}^{*}$, Dong-Min Xi, Sa-Sa Guo, Yan-Jie Fu \\ College of Electric Power, Inner Mongolia University of Technology, Huhhot 010080, China
}

\begin{abstract}
Wind/PV/storage system has the advantages of good power supply performance, few geographical limitations, and reasonable investment in equipment, and gradually becomes the priority project of developing independent wind power system preference in most remote areas. Based on the analysis of the constraint conditions of wind/PV/storage independent system, this paper discusses the capacity configuration model, process and strategies of wind/PV/storage independent system in detail, and considers practical solutions to power supply requirements in local areas without electricity, at the same time, it provides technology and practical basis for solving the key technical issues of independent power grid construction in remote areas.
\end{abstract}

Keywords: Wind / PV/storage, capacity configuration, model, strategies

\section{Introduction}

Currently, in the European Union, the United States, Canada, Japan and other countries, a new round of energy revolution, which is in direction of energy diversification and clean, in order to optimize the energy structure and promote the transformation of energy strategy, and characterized by clean energy and smart grid, is advancing worldwide [1]. The goal of social development in China has been changed to build a society with resource-saving, environment-friendly, sustainable development, which becomes the consensus of the whole country [2]. At present, distributed generation technology, micro-grid technology and smart grid technology, respectively, are at different stages of development. Policy support also speed up the promotion and application of distributed generation technologies.

China has a vast territory, complex terrain, and broad distribution of people, thus establishing a large power supply system covering all users to supply power is very uneconomic. For those areas without electricity away from the public network, and some special occasions, such as remote rural, pastoral areas, islands and others which are difficult to be covered by the power grid, using independent power supply system of new energy to provide production and living electricity is a more appropriate choice [3]-[4]. After investigating natural resource conditions of these areas, according to those resources to develop new energy power reasonably, integrating three networks of wind power, photovoltaic power generation, and energy storage systems as one, makes up for the defects of wind power and opto-electrical independent systems on the natural resources [5]. Supplemented by battery power storage, a truly independent off-grid system is built. Using solar and wind energy resources existing in the research areas for power generation reasonably, can ensure the reliability of the power generation, but also can reduce the cost of power generation. And it reflects the developing direction of the energy diversification and clean, at the same time the power supply needs in local areas without electricity are solved [6]. In the eyes of technical and economic evaluation, the wind/PV/storage independent system is a reasonable way of generating electricity.

\footnotetext{
* Manuscript received April 15, 2013; revised July 10, 2013.

The research funded by the Institution of Higher Learning Science Research Project under Grant No. NJZY13122 and the Natural Science Foundation of Inner Mongolia under Grant No. 2013MS0707.

Corresponding author. Tel.: +86-0471-3602300; E-mail address: hulinjingrjx@163.com.
} 
Wind power is greatly limited by the natural conditions, which leads to the output of wind power with a lot of randomness and instability [7]. For the low energy density and the randomness of wind energy, it is infeasible to provide a stable power relying on separate wind power or independent solar power generation. Even if this can be done, a heavy price must be paid. Such as increasing the capacity of the intermediate accumulator means (using battery is a common method), its high initial investment becomes the bottleneck of its development and use [8]. In order to better reduce the capacity of the battery, wind/PV/storage system is more suitable for these areas. Reference [9] concluded from the quantitative point that wind/PV/storage power generation system has stable power output and more reasonable investment. Wind/PV/storage power generation system can be well compatible with a variety of distributed power, provide a safe and reliable supply of electricity, and achieve the energy optimization of local network level. As a connecting link between the preceding and the following, Wind/PV/storage power generation system has practical solutions to power supply requirements in local areas without electricity, at the same time, it provides technology and practical basis for solving the key technical issues of independent power grid construction in remote areas. How to optimize the capacity configuration of a wind/PV/storage system, and make it satisfy the load and the total investment cost minimum, will be one of the hot research spots of this field in the next few years.

\section{Overview of Wind/PV/Storage Independent System}

As the production characteristics and investment of wind turbines, solar photovoltaic power generation, and energy storage element are different, to find the optimal configuration of the specific capacity of different devices in the system, it is necessary to consider the specific circumstances of the operating characteristics and loads of various types of devices. Through energy scheduling strategy, to control factors such as the rational energy flow between each device in the system, ultimately the purpose of reasonable investment, safe, reliable and economic operation is achieved.

Wind/PV/storage independent system refers to an independent power supply system which is composed by a wind generator, energy storage components and photovoltaic power generation [10]. This power supply system gives priority to wind power, photovoltaic power generation as a supplement, and energy storage element playing a role of buffer coordination. The main purpose of the research is, in the case of the user loads are met, also various types of constraint conditions, to research optimal configuration of the system capacity. In other words, in the premise that the load demand and supply quality are met, determine the structure of the specific capacity of the system.

Build power balance equation of wind/PV/storage system, as shown in Formulation 1,

$$
P_{w}+P_{x}+P_{c}=P_{l}
$$

where $P_{w}, P_{x}, P_{c}, P_{l}$ are expressed as follows,

$\begin{array}{llll}P_{w} & \text { output of the wind generator(MW). } & P_{x} & \text { electric power that battery charges /discharges (MW) } \\ P_{c} & \text { output of solar power. } & P_{l} & \text { load of users (MW) }\end{array}$

The structure of system is shown in Fig. 1.

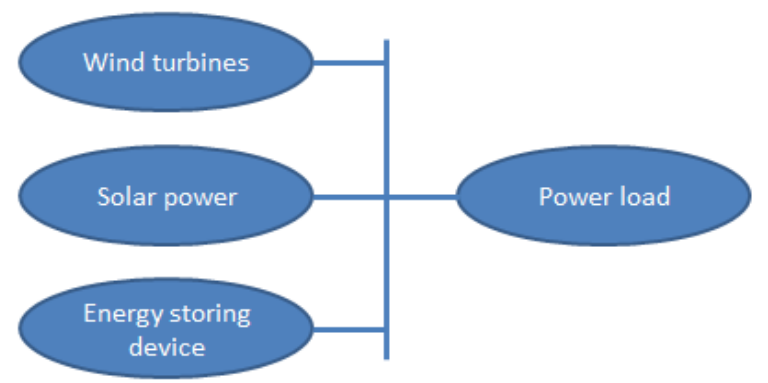

Fig. 1. Structure of wind/PV/storage system. 
According to the observational data provided by Bureau of Meteorology in the study area, the region can be rayed for 4452.7 a year on average, 2916.5 hours of sunshine, and the percentage of sunshine is $66 \%$. It is from 5:00am to 19:00pm in summer, 8:00am to $16: 00 \mathrm{pm}$ in winter.

According to the data provided by the NASA satellite meteorological database, the study of solar energy resource is on the middle level. Solar energy resource in summer is quite different from that in winter, however, it can be used in general. Snow factors should also be considered for photovoltaic power generation in winter.

Table 1. Monthly mean daily solar radiation of ground plane ( $\mathrm{kWh} / \mathrm{m} 2 /$ days)

\begin{tabular}{lllllll}
\hline \hline Year & 1 & 2 & 3 & 4 & 5 & 6 \\
\hline Annual average & 1.65 & 2.67 & 4.13 & 5.29 & 6.30 & 6.15 \\
Month & 7 & 8 & 9 & 10 & 11 & 12 \\
Annual average & 5.53 & 5.10 & 4.04 & 2.78 & 1.88 & 1.33 \\
\hline \hline
\end{tabular}

According to the observational data provided by Bureau of Meteorology, annual average wind speed at the height of $70 \mathrm{~m}$ is $7.2 \mathrm{~m} / \mathrm{s}$ in study area, and the annual average wind power density is $504.0 \mathrm{~W} / \mathrm{m}^{2}$, belonging to the 4th level. Annual effective wind speed hours are 7318h $(3 \sim 25 \mathrm{~m} / \mathrm{s}), 315 / \sim 360 /(\mathrm{NW} \sim \mathrm{N})$ prevalently. Wind direction is relatively stable.

\section{Capacity Configuration Model of Wind/PV/Storage Independent System}

The key problem of optimal capacity configuration is to find the solution of the wind/PV/storage system. The goal is to make the planning investments and running costs minimum, simultaneously reliability of the system highest, under the conditions that system loads and all kinds of constraint conditions have been met [11].

The objective function of the capacity configuration optimal model for independent wind/PV/storage system can be expressed as,

$$
\left\{\begin{array}{l}
\min f_{1}(k x, y)=F_{\Sigma} \\
\max f_{2}(k x, y)=R_{e l}
\end{array}\right.
$$

where

$$
F_{\Sigma}=\sum_{t=1}^{T}\left(C_{t}+W_{s t}\right)(1+r)^{-t}+\sum_{t=1}^{T}\left(F_{g t}+F_{k t}-B_{t}\right)(1+r)^{-(t-0.5)}
$$

and

$x \quad$ installed capacity of wind power of system (MW).

$k \quad$ proportion magnification factor, representing how wind power capacity to expand in the system.

$R_{e l} \quad$ reliability index.

$y \quad$ capacity of solar power and battery.

$F_{\Sigma} \quad$ calculated totally cost of the planning capacity of the wind/PV/storage systems.

$C_{t} \quad$ the equipment investment cost of system in year $t$.

$W_{s t} \quad$ grid investment costs in year $\mathrm{t}$.

$F_{g t}, F_{k t}$ maintenance fees for fixed operation and other expenses in year $t$.

$B_{t} \quad$ other benefits of the system in addition to electricity generation in year $t$.

$T \quad$ the years of the planning period $(n)$.

$r$ discount rate. 
What can be drawn by the formula (2) is wind/PV/storage capacity configuration optimization is a multi-objective programming problem consisting of two sub-goals. One is economic goal-the minimum total calculated costs, the other one is reliability - the best reliability of the system or a certain level of reliability [12]. Under the premise of meeting the reliability requirements of system, the one that coats the least on average each year will be the priority program.

Constraints of model:

\subsection{Constraint of system requirements and related operation}

System demands constraints, that is, at any time, the sum of the generating capacity of the power generation system must meet the total electricity demand of system loads,

$$
P_{c}+P_{x}+P_{w}=P_{L}(1+\sigma+\rho)
$$

where

$P_{c} \quad$ capacity of solar power generation at time $t$.

$P_{x} \quad$ power capacity of the battery charges/discharges.

$P_{w} \quad$ capacity of wind turbines at time $t$.

$P_{L} \quad$ users load of the system at time $t$.

$\sigma, \rho \quad$ power plant electricity rate and system line loss rate.

\subsection{Constraint of the maximum and minimum output for wind turbine}

$0 \leq P_{w . t} \leq P_{w \cdot \max }$

where $P_{w . t}$ is the output of wind turbine at time $t$ and $P_{w \cdot \max }$ is the maximum output of wind turbine.

\subsection{Constraint of the maximum and minimum output for solar power}

$0 \leq P_{c . t} \leq P_{c . \max }$

where $P_{c . t}$ the output of the photovoltaic power generation; $P_{c \cdot \max }$ the maximum output of the photovoltaic power generation

\subsection{Constraint of total storage capacity of the battery}

$$
0 \leq P_{x . t} \leq P_{x . \max }
$$

and

$$
P_{x . t}=\left(P_{w}+P_{c}-P_{L}\right)(1+\beta)+P_{x \cdot(t-1)}
$$

where $P_{x . t}$ is the power stored by the battery at time $t, P_{x \text { max }}$ is the maximum storage power of Battery, and $\beta$ is the electric efficiency that Battery charge/discharges.

\subsection{Constraint of system reserve capacity}

Power supply of power system not only should meet the load demand, there should also be a certain amount of reserve capacity in order to ensure reliability of supply and the electrical energy quality.

Constraint of system reserve capacity is:

$$
X_{i t}+P_{z o}-P_{L . m t}(1+\rho+\sigma) \geq C_{B t} \quad t=1,2 \ldots, T
$$

where 
$X_{i t} \quad$ new installed capacity of wind turbines in year $t$.

$P_{z o} \quad$ original installed capacity of the system

$P_{L . m t} \quad$ the maximum load of the system in year $t$.

$C_{B t} \quad$ reserve capacity that system should have in year $t$.

\subsection{Constraint of wind power installed capacity by terrain resources}

$0 \leq N W T G \leq \max N W T G$

where NWTG is the number of installed sets in wind farm, and maxNWTG is the maximum number of installed sets of wind turbines in the region. In some areas, the number of installed wind turbine sets is not only limited by local wind energy resources, but also by local geographical conditions.

\section{Capacity Configuration Optimization Process}

Steps to solve independent wind/PV/storage system capacity configuration optimization are shown in Fig. 2.

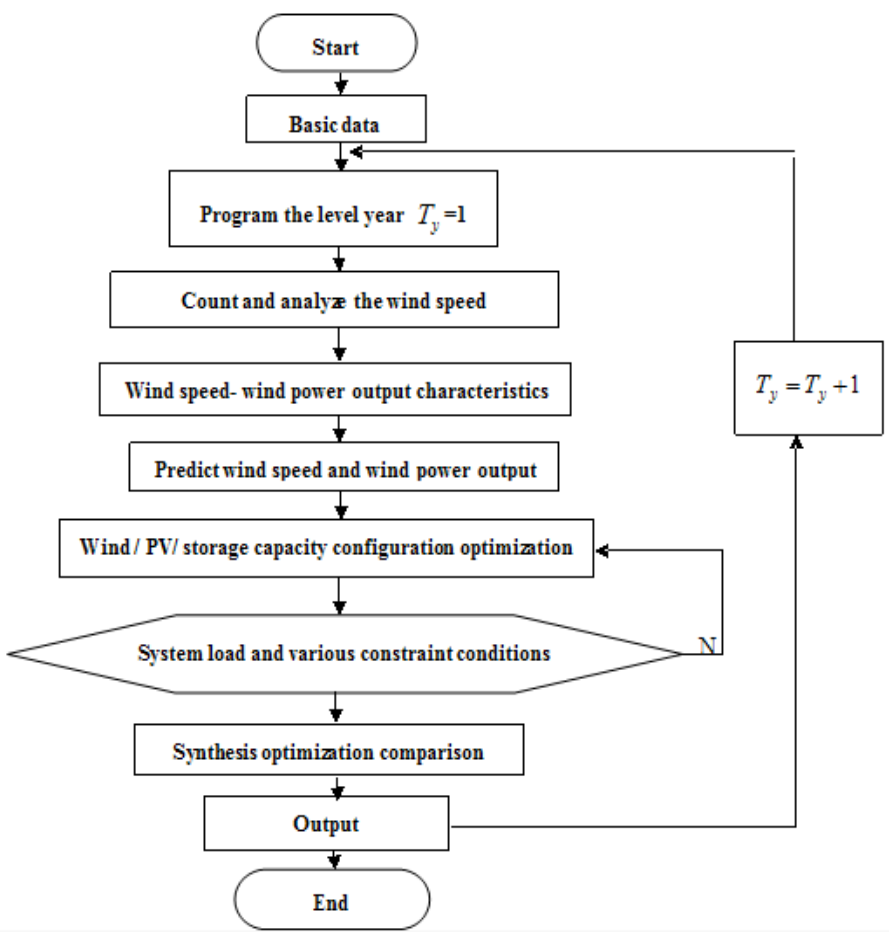

Fig. 2. Capacity configuration optimization flow char.

1) Basic data: including solving the loads, hourly wind speed data, and hourly output of wind turbine in level year $T_{y}$.

2) To count and analyze the wind speed characteristics, that is to obtain monthly wind speed characteristics according to hourly data of wind speed in one year.

3) Wind speed- wind power output characteristics, corresponding relationship between wind speed and wind power output can be obtained from the corresponding curve of the two. According to the data of step 2 monthly total wind power output can be get through the monthly wind speed characteristics.

4) Predict the wind speed of the wind farm and get short-term prediction of wind speed. Wind power output forecast can be get from wind speed - wind power output characteristic relationship from above. 
Then evaluate the result of the forecast.

5) Predict the wind power output directly and evaluate the result of the forecast.

6) Plan the level year $T_{y}$. Wind power output and loads have been given. In the circumstances that constraints meeting the load and system are known, determine the installed capacity of wind power, solar power and battery, and obtain installed capacity program.

7) Compare the average annual total cost of the capacity program, then select the better program.

\section{Wind/PV/Storage System Energy Configuration Policy}

The main task of the energy configuration policy is, fully considering the characteristics of all kinds of electrical generating and storage devices and user loads in system, and arranging power generation parts' working conditions on hourly load curve according to certain principles. Finally, when the power loads have been ensured, the capacity and calculating cost of each power generation component are obtained, and then, select the best results after comparison.

Specific strategies are as follows:

1. When the instantaneous power of the wind turbine is greater than total loads, it will supply for all the loads. If the battery does not reach the upper limit of charging, the battery will charge. If it dose, unloading will be started, and the spare power will be removed [13].

$$
P_{w . t}=P_{L . t}+P_{x . t}
$$

where $P_{w . t}$ is the instantaneous output of wind turbine at time $t, P_{L . t}$ is the load power at time $t$, and $P_{x . t}$ is the instantaneous power that battery charges at time $t$.

2. When the instantaneous power of the wind turbine is equal to the instantaneous power of the loads, all of the loads are supplied, and the battery remains unchanged.

$$
P_{w . t}=P_{L . t}
$$

3. When the instantaneous power of the wind turbine is less than total loads, part of loads are supplied by all wind power output, other by battery discharging.

$$
P_{w . t}+P_{x . t}=P_{L . t}
$$

In wind/PV/storage system simulation, wind power is first, solar photovoltaic power as supplementary, also regulating the system fluctuations [14]. According to hourly system curve values of daily loads, determine the wind power output first, and then judge the work status of the battery, to make the instantaneous power and instantaneous load of users equal one by one.

\section{Conclusions}

Both wind and solar energy have natural complementarity, so that building solar and wind hybrid system will be a developing direction. Wind/PV/storage system has the advantage of good power supply performance and reasonable investment in equipment, and gradually becomes the priority projects of developing independent wind power system preference in most remote areas.

This paper briefly describes the wind/PV/storage independent system, discusses the model of capacity configuration and constraints, and proposes optimizing processes and energy scheduling policy. According to hourly load curve of the system, determine the working status of the power generation parts based on certain principles, then the best generation capacity and costs can be drawn. This research can provide technical and practical basis for independent power grid construction in remote areas. 


\section{References}

[1] Ma YF. The analysis and forecasting of chin's energy demand based on economy growth. MS thesis. North University of China. Taiyuan, China; 2009.

[2] Zhang LJ. Research on regional energy efficiency and the influential factors. Technical Economy and Management Research, 2011; 04:74-77.

[3] Shi JH, Liu CJ. Realistic analysis and policy options for Chinese ethnic regions to develop renewable energy. Guangxi Ethnic Study, 2008; 4:149-154.

[4] Fang Y. Optimal matching design example of wind and solar energy hybrid independent power supply system. Energy Conservation, 2011; 30(3):34-36.

[5] Li DF. Development of China off-grid wind power industry in 2008, Agriculture Engineering Technology (New Energy Industry), 2009; 4:5-8.

[6] Zhang Z. Countermeasures of Inner Mongolia wind power industry development under low-carbon economy background. Northern Economy, 2011; 10:46-48.

[7] Guan J, Gao CW. An overview on the application of energy storage technologies to damp wind power output fluctuation. Power System and Clean Energy, 2011; 27(4):48-53.

[8] Wang B. A new optimal design of hybrid wind/PV power system. MS thesis. Jiangnan University. Wuxi, China; 2008;2-15

[9] Diaf S, Dialf D, Bellhamel M. A methodology for sizing of autonomous hybrid PV/Wind system. Energypolicy, 2007; (3):1416-1423.

[10] Zhang ZW, Cao D. Study on hybrid wind/PV/energy storage system optimal capacity configuration. Sichuan Electric Power Technology, 2013; 36(1):37-43.

[11] Xu DM. Optimal design of standalone hybrid wind/PV power system. Acta Energiae Solar Sinica, 2006; 9:919-922.

[12] Li ZH. Wind\&hydro system planning issues study. Huazhong University of Sciences and Technology. Wuhan, China; 2008; 20.

[13] Zhao JD. Optimal design of wind-solar-diesel-battery hybrid power generation system based on genetic algorithm. Power System and Clean Energy. 2011; 27(1):56-59.

[14] Ding M, Wang B, Zhao B, Chen ZN. Configuration optimization of capacity of standalone PV-wind-diesel-battery hybrid microgrid. Power System Technology, 2013; 37(3): 575-581. 